\title{
Comparative analysis of cascaded Fuzzy-PI controllers based-MPPT and perturb and observe MPPT in a grid-connected PV system operating under different weather and loading conditions
}

\author{
Harici Otmane $^{1}$, Mouloudi Youssef ${ }^{2}$, Bendjebbar Mokhtar ${ }^{3}$ \\ ${ }^{1,2}$ Departement of Electrical Engineering, University Tahri Mohammed Bechar, Algeria \\ ${ }^{3}$ Departement of Electrical Engineering, University USTO Oran, Algeria
}

\begin{tabular}{l}
\hline \hline Article Info \\
\hline Article history: \\
Received Feb 29, 2019 \\
Revised Mar 7, 2019 \\
Accepted May 28, 2019 \\
\hline Keywords: \\
FLC \\
MPPT \\
P\&O \\
PI \\
PV
\end{tabular}

\begin{abstract}
In this paper, a comparison is carried out between MPPT technique using a hybrid cascaded Fuzzy-PI Controller and Perturb and Observe (P\&O) MPPT technique. The two techniques are compared in a system which consists of a photovoltaic system connected to a grid via a two-level three-phase inverter. The P\&O and Fuzzy-PI techniques are examined under different weather conditions, namely, ramp change in irradiation level and ramp change in temperature levels. Disturbances represented by fluctuations in power demand from the utility grid is generated to assess the robustness of each of the two controllers. The Fuzzy-PI based MPPT, has proved its excellent tracking and robustness against abrupt perturbations. Simulations of the system performances using the two regulators are performed to validate the conceptual standings.
\end{abstract}

Copyright (C) 2019 Institute of Advanced Engineering and Science. All rights reserved.

\section{Corresponding Author:}

Harici Otmane,

Departement of Electrical Engineering

University Tahri Mohammed Bechar,

BP 1505, El M'naouer, 31000, Oran, Algeria

Email: otmane.harici@univ-usto.dz

\section{INTRODUCTION}

The global energy infrastructure depends heavily on burning fossil fuels. These resources are polluting the environment and are depleted at faster pace. To address this concern, Solar Energy can be harvested using the Photovoltaic (PV) technology which offers a clean and renewable source of electricity. To date, this way of electricity generation, however, has been relatively costly. Very often, the success of a PV application depends on whether the power electronics device can extract sufficiently high power from the PV arrays to keep overall output power per unit cost low. A PV array operating a the maximum power point (MPP) can be used to provide electricity for rural areas, especially in developing countries where the grid is rarely fully extended because of profitability and other financial considerations.

The PV module generates its maximum power at a single operating point. On the other hand the operating point of a PV system can be controlled by adjusting the output load or output voltage of the PV system. The process of driving the PV system to operate near this single point is referred as Maximum Power Point Tracking (MPPT). Controlling the output voltage of the PV system via a power electronic converter is the most common way, which, in turn, is usually controlled via a specific control algorithm to drive this action. Several MPPT algorithms have been proposed such as the constant voltage, the constant current, the look-up table, the pilot cell, the Perturb and Observe (P\&O), the Incremental Conductance (IC) [1], the ripple correlation method and the sliding mode control (SMC). In addition, artificial intelligence-based methods have also been investigated such as the Fuzzy Logic $[2,3]$ and the Artificial Neural Networks (ANNs) thanks 
to their distinctive feature of not requiring the exact model of the system, robust structures, etc. Other works concentrate on improving fuzzy methods by combining it to other intelligent approaches such as Neural Networks, Particle Swarm Optimization and Genetic Algorithm [4-6]. These studies show that the fuzzy control algorithm is capable of improving the tracking performance as compared with the conventional methods for both linear and nonlinear loads. However, only isolated load has been considered in these schemes.

In this paper, a comparison between Fuzzy Logic Controller (FLC) and Perturb and Observe (P\&O) is proposed for maximum solar power tracking of the PV array which is connected to a three-phase grid by a line commutated SCRs inverter. The FLC only requires the linguistic control rules for MPPT. This paper proves that the FLC control strategy can significantly improve the tracking accuracy and speed of the MPPT control. Conclusions are finally drawn in the last section.

\section{MATHEMATICAL MODEL}

The building block of PV arrays is the solar cell, which is a p-n semiconductor junction, shown in Figure 1. The $V, I$ characteristic of a solar array is given by (1) [7].

$$
I=I_{S C}-I_{0}\left\{\exp \left[\frac{q\left(V+R_{S} I\right)}{n k T_{k}}\right]-1\right\}-\frac{V+R_{S} I}{R_{S h}}
$$

where $V$ and $I$ represent the output voltage and current of the PV, respectively; $R_{S}$ and $R_{S h}$ are the series and shunt resistance of the cell; $\mathrm{q}$ is the electronic charge; $I_{S C}$ is the light-generated current; $I_{0}$ is the reverse saturation current; $n$ is a dimensionless factor; $k$ is the Boltzman Constant and $T_{k}$ is the temperature in $\mathrm{K}^{\circ}$.

In term (1) was used in computer simulations to obtain the output characteristics of a solar cell, as shown in Figure 2. This curve clearly shows that the output characteristics of a solar cell are non-linear, are crucially influenced by solar radiation and temperature. Each curve has a MPP, at which the solar array operates most efficiently.

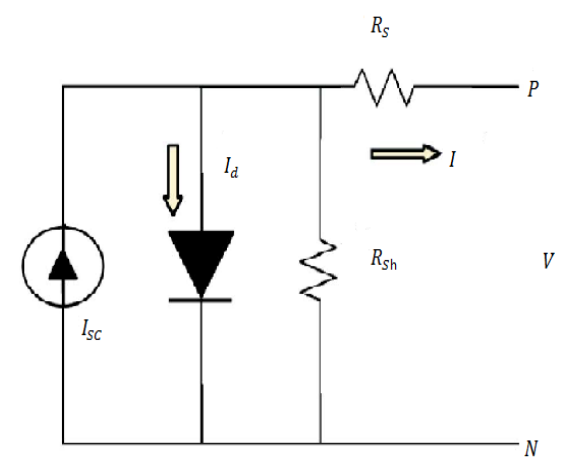

Figure 1. Equivalent circuit of PV array.

(a) I-V Curves at $\mathrm{T}=25^{\circ} \mathrm{C}$

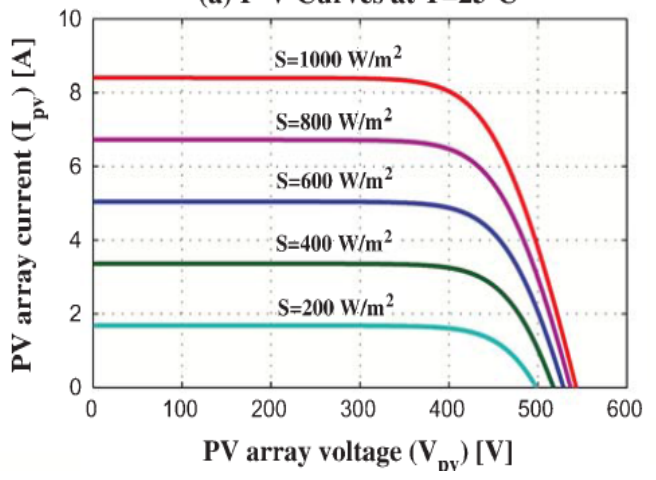

(b) I-V Curves at $\mathrm{S}=1000 \mathrm{~W} / \mathrm{m}^{2}$

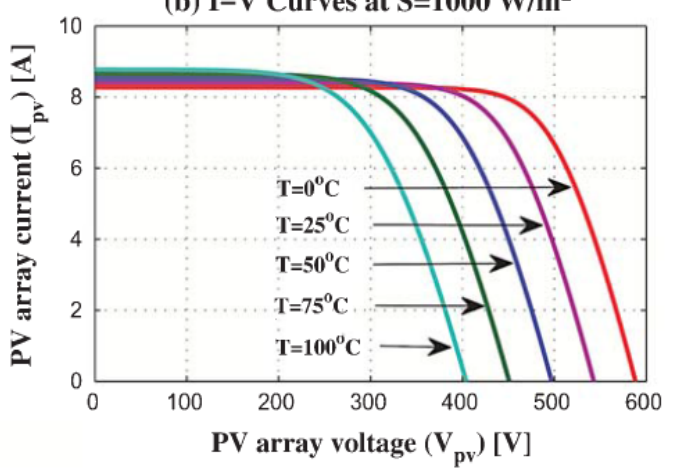



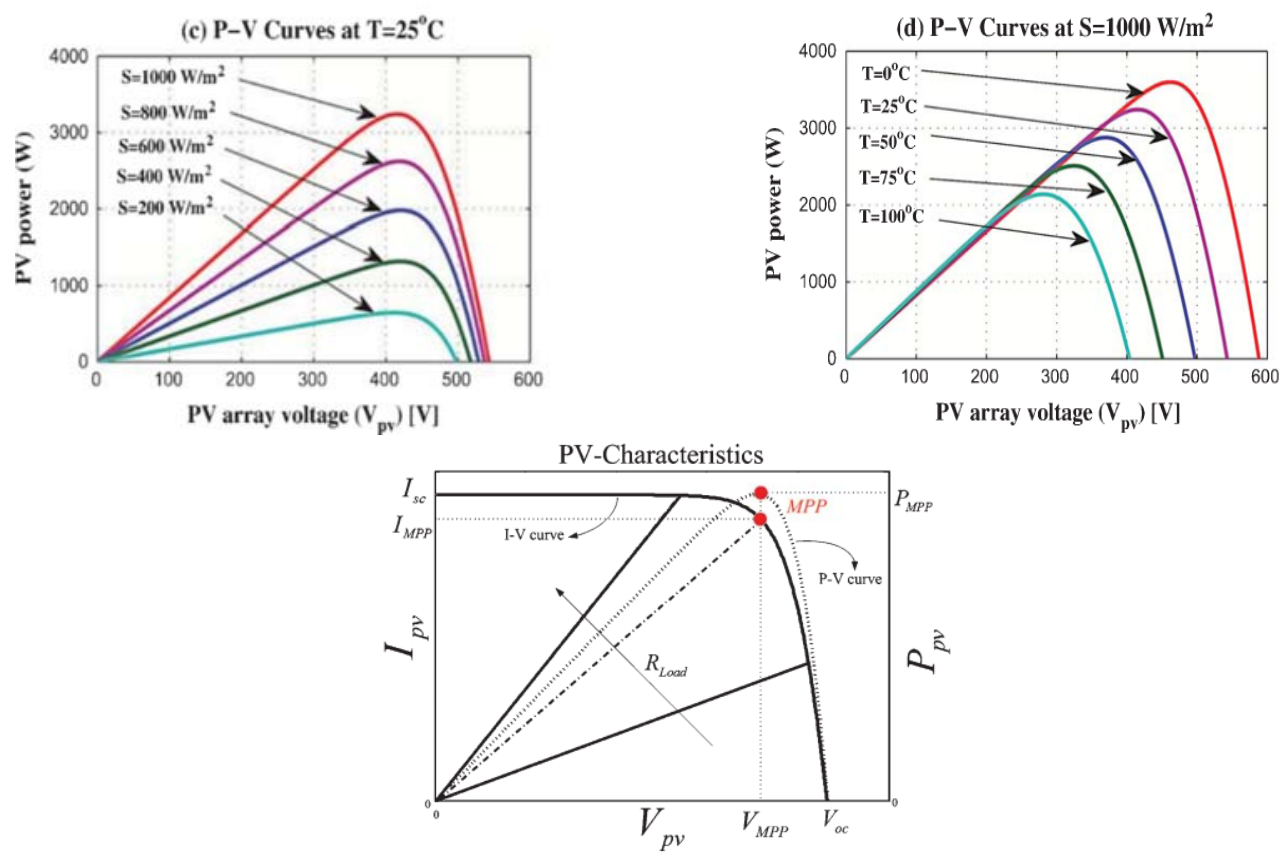

Figure 2. (a) Current-voltage and power-voltage characteristics of PV array.

(b) schematic of MPPT process [8].

\section{MPPT CONTROL TECHNIQUES}

\subsection{Perturb and observe (p\&o) technique}

It is the most used technique since it ensures continuous search for the maximum power point of a photovoltaic generator. It is based on the disturbance of the voltage or current at the PV terminals and then the observation of the effect of this variation on the output power [9]. If the current power value $\mathrm{P}(\mathrm{k})$ of the panel is greater than the previous value $\mathrm{P}(\mathrm{k}-1)$ then the same previous disturbance direction is kept. Otherwise, disturbance in the reverse direction is generated [10]. Figure 3 shows the structure of this technique.

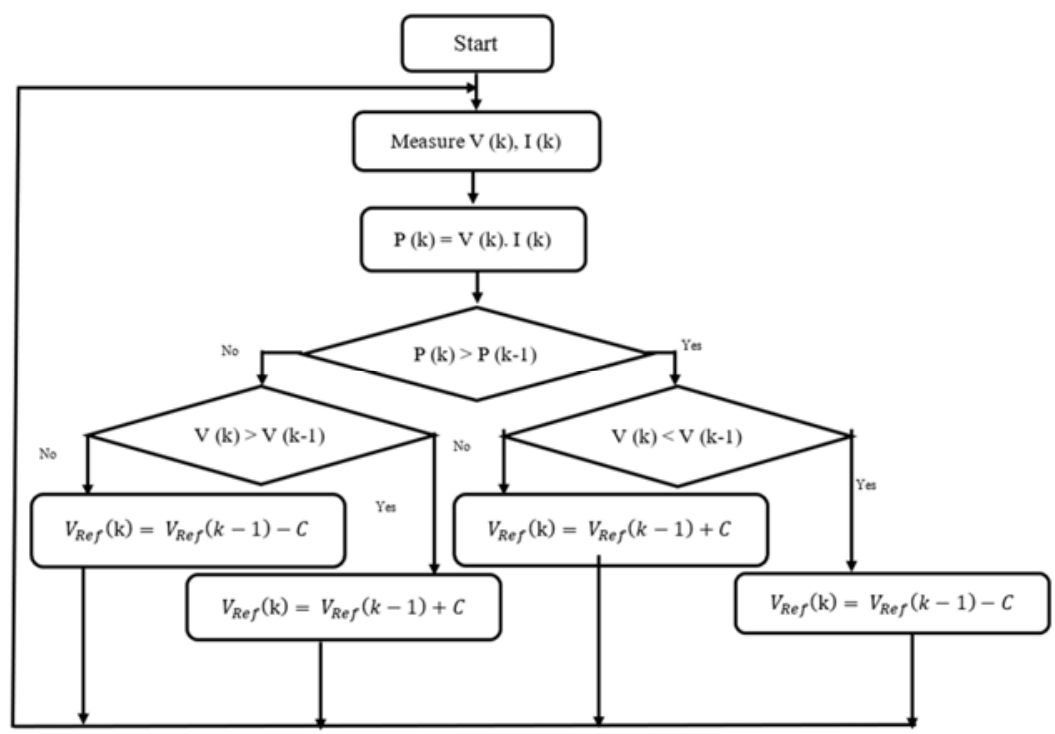

Figure 3. Organization chart of the technique perturb and observe 


\subsection{The FLC based MPPT algorithme}

Classical controllers (P, PI, PID) are feedback controllers with fixed parameters. Therefore, they do not be able to adapt with environmental changes and to compensate parameter variations in plant. On the other hand, in a classical controller, first, it is necessary to find a proper mathematical model for plants; and then tune controller parameters and implement the designed controller. Because of nonlinear behavior of most real systems and difficulties in their modeling, classical controllers are not useful in nonlinear control applications. In order to overcome such kind of problems and to have a well-tuned controller for whole range of operating points, other control strategies, like adaptive control, intelligent control or fuzzy logic control, have got great concerns [11-13].

Fuzzy Logic Controllers are one of the most successful applications of the fuzzy sets [14]. They use linguistic variables as human beings do rather than numerical variables and have the advantages of working with imprecise inputs, not requiring an accurate mathematical model of the system, and handling nonlinearities. The fuzzy control theory allows designers to use non-precise or ill-defined concepts. The nonlinear and adaptive nature of FLC provides robust performance even under parameter variations and external disturbances; therefore, it provides superior MPPT performance even under rapidly changing atmospheric conditions.

The general structure of the FLC is shown in Fig. 4. It is composed of a fuzzifier, a knowledge base, an inference engine and a defuzzifier.

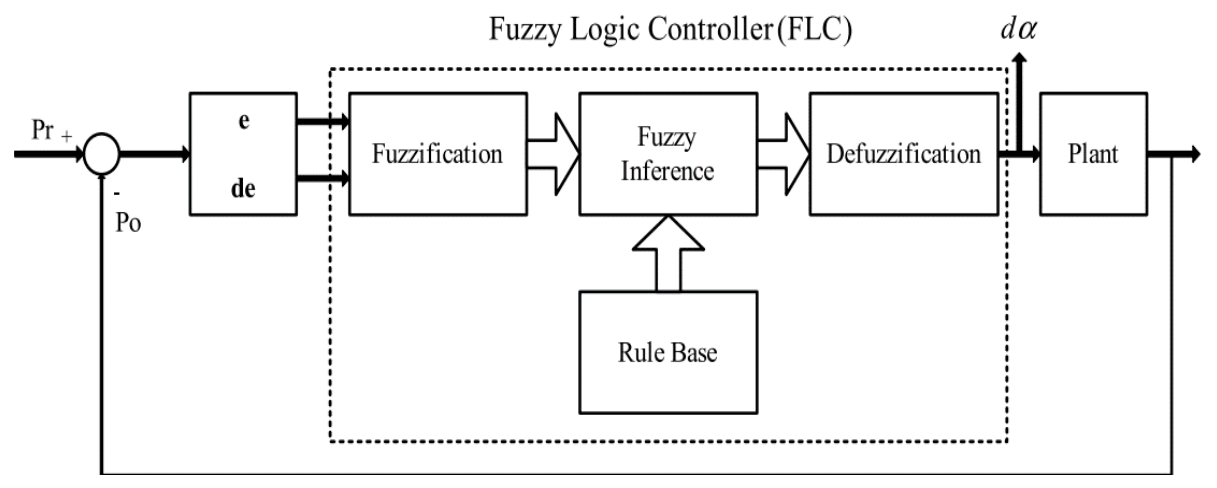

Figure 4. A FLC in closed loop control system.

Defining the input and output variables is one of the most important steps in the FLC design. In this work, an FLC with two inputs and one output is designed as an MPPT algorithm. The change in PV power $(\mathrm{dp}=\mathrm{dP} / \mathrm{dt})$ and the change in PV voltage $(\mathrm{dv}=\mathrm{dV} / \mathrm{dt})$ are used as inputs of the FLC, while the output variable is defined as the change in duty cycle $(\mathrm{dD})$ of the boost converter. An integrator is used at the output of the FLC to obtain the duty cycle value of the boost converter. Seven triangular membership functions are used for both input and output variables of the FLC, as shown in Figure 5. As we can see, linguistic labels such as positive large (PL), positive medium (PM), positive small (PS), zero (Z), negative small (NS), negative medium $(\mathrm{NM})$ and negative large $(\mathrm{NL})$ are used for these input and output membership functions.

The required linguistic definitions about the input and output variables and rule base are stored in the knowledge base. The rule base consists of some fuzzy rules expressed in the IF-THEN fuzzy conditional statements and maps the relations between inputs and outputs. The rule base of the FLC is determined as given in Table 1, including 49 rules that are set based upon the knowledge and working of the system.

$$
\begin{aligned}
& E(k)=\frac{P(k)-P(k-1)}{V(k)-V(k-1)} \\
& C E(k)=E(k)-E(k-1)
\end{aligned}
$$

In the case of our study, the blurred controller entry is error (E), error change (CE) represents. And output $\alpha$ (alpha) Duty cycle 


\begin{tabular}{rlllllll}
\multicolumn{10}{c}{ Table 1. Fuzzy Rule Base for studied design } \\
\hline $\begin{array}{rllllll}\text { ce } \\
\text { error }\end{array}$ & NL & NM & NS & Z & PS & PL & PM \\
& & & & & & \\
\hline NL & PL & PL & PL & PL & NM & Z & Z \\
NM & PL & PL & PL & PM & PS & Z & Z \\
NS & PL & PM & PS & PS & PS & Z & Z \\
Z & PL & PM & PS & Z & NS & NL & NM \\
PS & Z & Z & NM & NS & NS & NL & NM \\
PL & Z & Z & NM & NL & NL & NL & NL \\
PM & Z & Z & NS & NM & NL & NL & NL \\
\hline
\end{tabular}

PL positive large; PM positive medium; PS positive small; Z zero; NS negative small; NM negative medium; NL negative large.

The inference engine acts like the human decision process and generates the fuzzy output depending on the knowledge of the control rules and the linguistic variable definitions. The active rules are determined by using fuzzified input variables and the rule base, and then these active rules are evaluated using fuzzy reasoning methods. In this work, the commonly used min-max inference method is used to generate the fuzzy control command. Finally, the defuzzifier converts the fuzzy control command to a real one. This action is called defuzzification and it is performed using the center of gravity method given by (4):

$$
X^{*}=\frac{\sum_{i=1}^{n} \mu\left(x_{i}\right) \cdot x_{i}}{\sum_{i=1}^{n} \mu\left(x_{i}\right)}
$$

where $X^{*}$ is the defuzzified value, $x_{i}$ is the sample element, $\mu\left(x_{i}\right)$ is the membership function and $n$ is the number of elements in the sample.
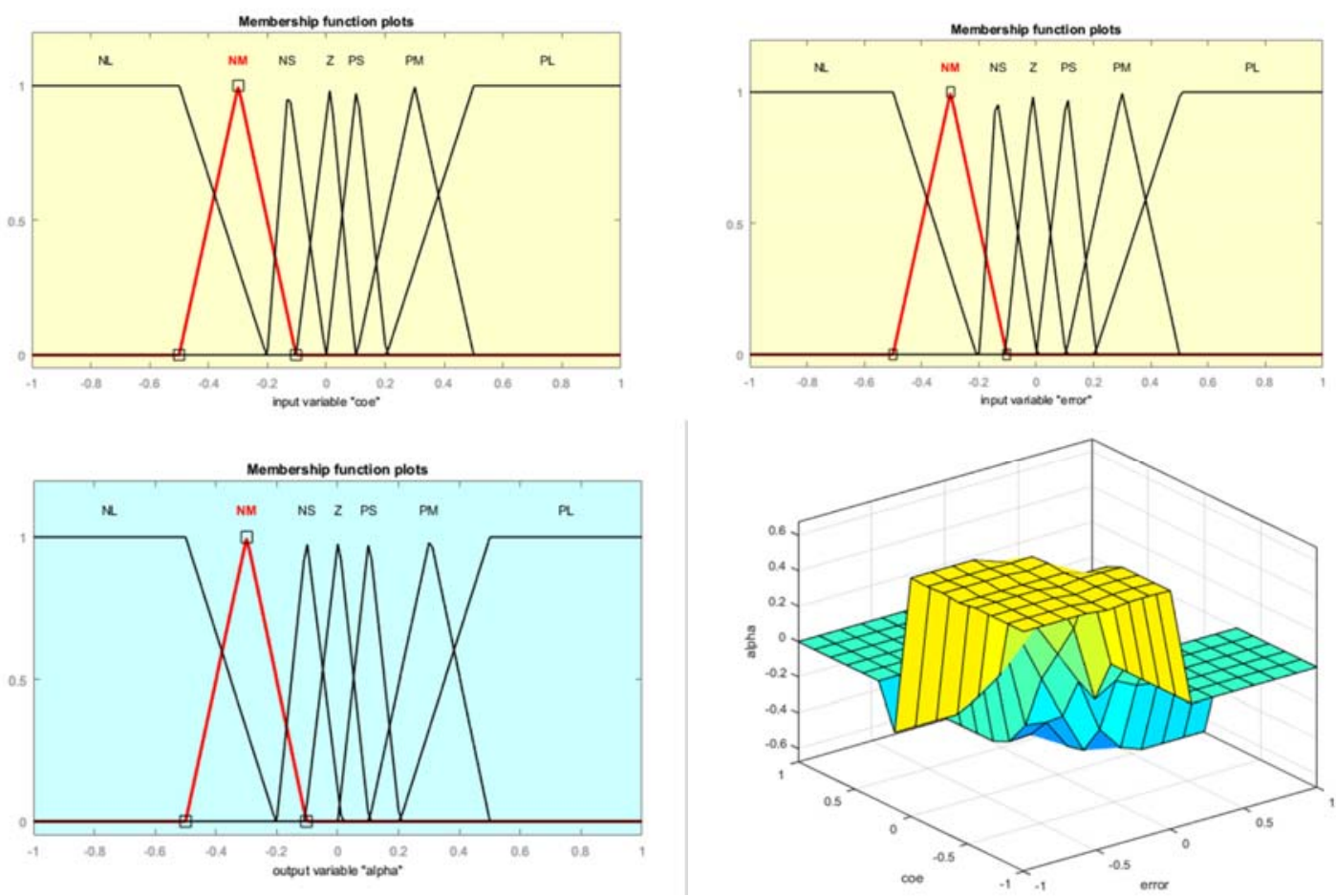

Figure 5. Triangular membership functions are used for both input and output variables of the FLC. 


\section{THE SIMULATION BLOCK DIAGRAM}

The proposed scheme in this paper is shown in Figure 6. This scheme is consist of some main parts which are a PV array, a boost DC/DC converter, a line commutated SCR inverter, a step-up transformer and the fuzzy logic controller.

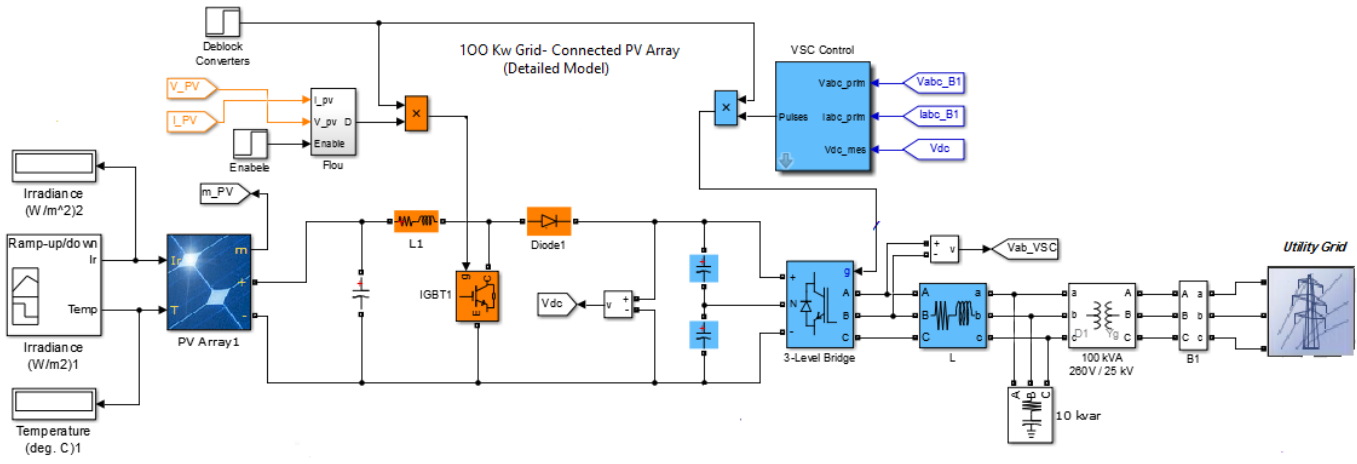

Figure 6. PV system with three-phase utility grid.

The PV array converts solar radiation into electrical power. The boost converter increases the level of produced DC voltage. The generated power is fed to the six-pulse thyristor bridge, which acts as a linecommutated inverter through dc link inductance. This inductance will be caused to obtain a steady direct current from the PV panels[15]. The line-commutated inverter transfers the power from the PV panels to the utility grid via the step-up transformer.

\section{RESULT AND DISCUSSION}

Operation of the above mentioned system using one of the two controllers (P\&O and FLC) is performed with a ramp change in irradiation level then a ramp change in temperature levels, as shown in Figure 7. performances of both controllers is assessed by considering the output voltage of the DC-link (the Boost converter output voltage). In addition, output power, voltage and current fed to the utility grid (i.e. at the high voltage side of the transformer.) is also considered. Finally robustness of the two MPPT techniques is examined by applying varying loads while measuring the output DC voltage as shown in figures 8 and 10 .
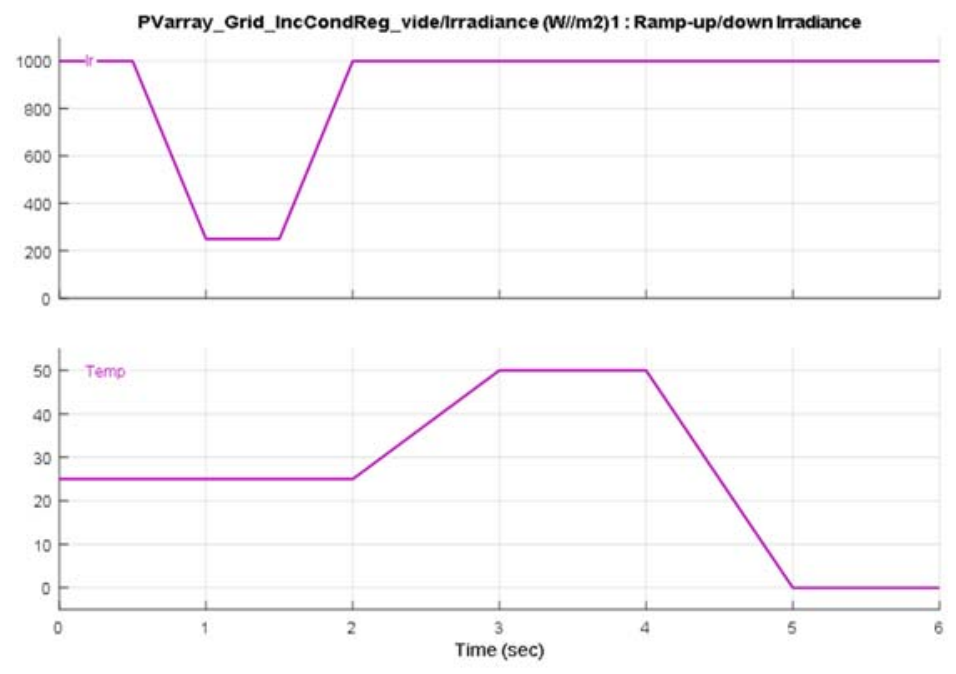

Figure 7. Simulated weather conditions (Irradiance and Temperature levels) 


\subsection{P\&O MPPT technique}

The following Figure 8 and 9 shows the different perturbation on the reference voltage Vdc it is the sortier of Boost and the voltage, current and the rated power load with the technique method P\&O MPPT.

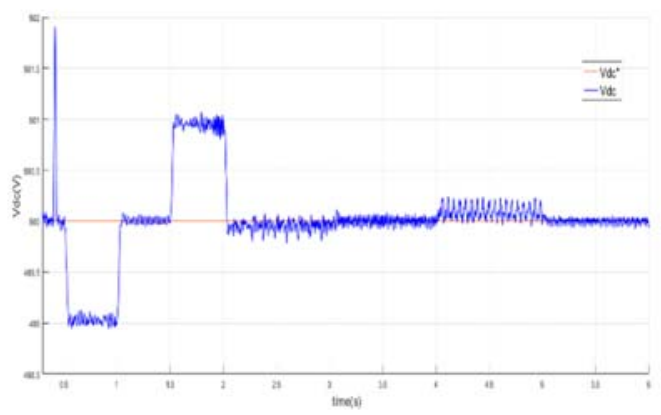

Figure 8. The Boost Converter Output Voltage using the P\&O MPPT
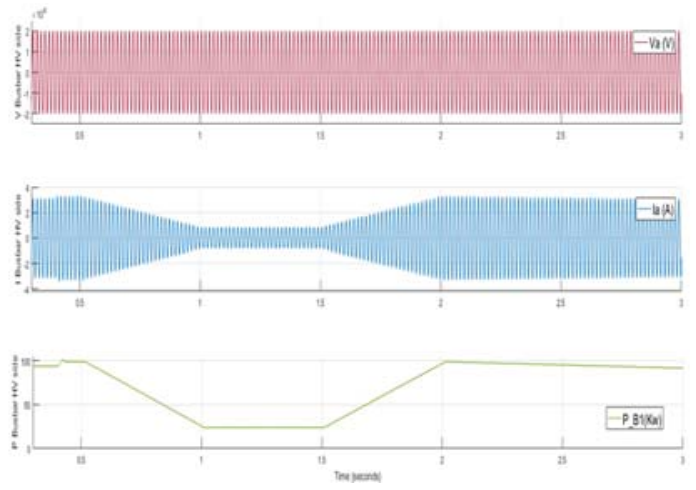

Figure 9. Simulated Voltage, Current and Power at transfomer HV side using the P\&O MPPT Algorithm

\subsection{Fuzzy-Based MPPT technique}

The following Figure 10 an 11 shows the different perturbation on the reference voltage Vdc it is the sortier of Boost and the voltage, current and the rated power load with the technique method Fuzzy-Based MPPT.

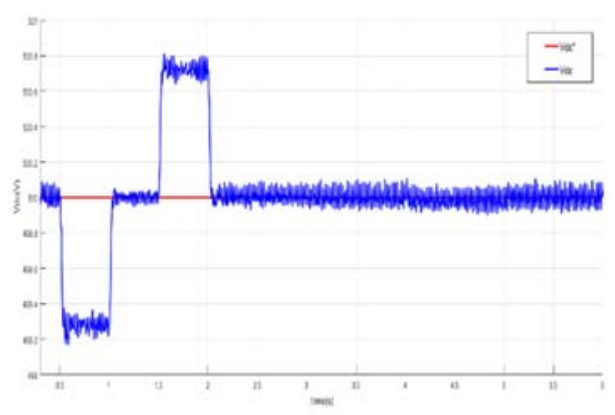

Figure 10. The Boost Converter Output Voltage using the FLC MPPT 

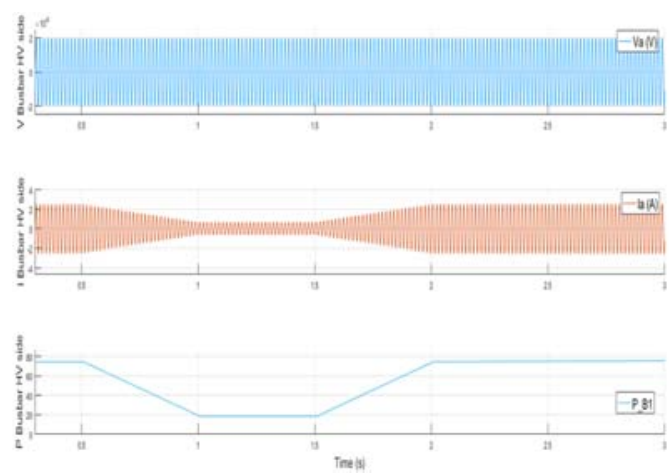

Figure 11. Simulated Voltage, Current and Power at Transfomer HV side using the FLC-Based MPPT Algorithm

\subsection{Analytical Comparison}

\subsubsection{Effect of Irradiance Variations}

At a fixed temperature level $\left(25^{\circ} \mathrm{C}\right)$, a ramp change has occurred in irradiance level in both cases. A voltage drop of $\Delta \mathrm{V}=1 \mathrm{~V}$ has resulted in output voltage of the boost converter when a $\mathrm{P} \& \mathrm{O}$ controller is used, while a slighter voltage drop of $\Delta \mathrm{V}=0.8 \mathrm{~V}$ has been noticed in case of using the Fuzzy Logic Controller.

\subsubsection{Effect of Temperature Variations}

At a nominal irradiance level $(1000 \mathrm{w} / \mathrm{m} 2)$, a ramp decrease in temperature level is simulated as shown in Figure 7. The change has caused a slight deviation of voltage ripples in the output voltage of the boost converter in case of using the P\&O MPPT algorithm. While a good tracking has been ensured by the FLC MPPT algorithm.

\subsubsection{Load Demand Variations}

Considering Figure 8, it is evident that the P\&O MPPT technique lacks robustness against sudden fluctuations in power demand; this disadvantage is highlighted in the following instances:

- Around 0.4 seconds: a significant overshoot has resulted in the output voltage of the boost converter.

- From 2 to 3 seconds: a remarkable dip in output voltage of the boost converter due to the ramp change in irradiance level as discussed previously.

- From 4 to 5 seconds: an overshoot is noticed during the ramp change in the PV temperature levels.

On the other hand, thanks to the adaptability of the fuzzy-PI controller, variations in system parameters (i.e. variation in load demand.). has not generated in peaks and it has guaranteed a stable voltage level at the output of the boost converter. Performance of the MPPT based on using the hybrid controller is illustrated in Figure 10.

\subsubsection{Comparison of Produced Power}

Although the produced power from the PV panels using the P\&O reached relatively higher level 100 $\mathrm{Kw}$ (see Figure 9), the produced power from the PV panels using the newly proposed hybrid controller has proven to be more robust in producing a stable voltage regardless of the sudden change in power demand while ensuring the production of an acceptable power of $80 \mathrm{Kw}$ (see figure 11). In other words, thanks to the use of a hybrid fuzzy-pi controller in tracking the maximum power the PV panels operated at $80 \%$ of its nominal power, which help to extend the lifetime and enhance reliability of the overall system.

\section{CONCLUSION}

In this paper, an comparative study is carried out between two controllers, namely, the P\&O MPPT controller and Fuzzy Logic Controller. Simulation results under different weather and loading conditions has proved the advantage of the FLC in terms of robustness and tracking.

\section{ACKNOWLEDGEMENTS}

Comparative analysis of cascaded Fuzzy-PI controllers based-MPPT and perturb ... (Harici Otmane) 
Authors would like to thank the heads of Laboratory Smart Grids the renewable energies (ENERGARID) at the university TAHRI Mohammed of Bechar (Algeria) and Laboratoire LDEE groupe Diagnostic at the university USTO of ORAN (Algeria).

\section{REFERENCES}

[1] H. Attia, "Fuzzy Logic Controller Effectiveness Evaluation through Comparative Memberships for Photovoltaic Maximum Power Point Tracking Function," International Journal of Power Electronics and Drive System (IJPEDS), vol. 9, no. 3, pp. 1147-1156, 2018.

[2] K. Rajasekhara Reddy, V. Nagabhaskar Reddy, M. Vijaya Kumar, "Control of Single Stage Grid Tied Photovoltaic Inverter Using Incremental Conductance Method," International Journal of Power Electronics and Drive System (IJPEDS), vol. 9, no. 4, pp. 1702-1708, 2018.

[3] Mohammed Slimi, Abdelkrim Boucheta, Bousmaha Bouchiba, "Maximum power control for photovoltaic system using intelligent strategies," International Journal of Power Electronics and Drive System (IJPEDS), vol. 10, no. 1, pp. 423-432, 2019.

[4] B. Bendib, F. Krimb, H. Belmilia, M.F. Almia and S. Boulouma, "Advanced Fuzzy MPPT Controller for a standalone PV system," Journal of Energy Procedia, vol. 50, pp. 383-392, 2014.

[5] M.R. Vincheh, A. Kargar and Gh.A. Markadeh, "A hybrid control method for maximum power point tracking (MPPT) in photovoltaic systems," Arab J Sci Eng vol. 39, pp. 4715-4725, 2014.

[6] Y. Kohata, K. Yamauchi and M. Kurihara, "High-speed maximum power point tracker for photovoltaic systems using online learning neural networks," J Adv Comput Intell Intellig Inform, vol. 14(6), pp. 677-683, 2010.

[7] Bose, B. K., Szczeny, P. M. and Steigerwald, R. L., "Microcomputer Control of a Residential Photovoltaic Power Conditioning System," IEEE Transactions on Industrial Electronics, vol. IA-21, pp. 1182-1191, 1985.

[8] L.K. Letting, J.L. Munda and Y. Hamam, "Optimization of a fuzzy logic controller for PV grid inverter control using S-function based PSO," J of Solar Energy, vol. 86, pp.1689-1700, 2012.

[9] Ramadhani Kurniawan Subroto, Sapriesty Nainy Sari, Zainul Abidin, Kuo Lung Lian, "Voltage Regulation of Boost Converter using Observer based Sliding Mode Controller," TELKOMNIKA (Telecommunication, Computing, Electronics and Control), vol.16, no.6, pp. 2896-2904, 2018.

[10] M. Hatti, "Contrôleur flou pour la poursuite du point de puissance maximum d'un système photovoltaïque," JCGE'08 LYON, 2008.

[11] Omid Zhoulai Bakhoda, Mohammad Bagher Menhaj and Gevork B. Gharehpetian, "Fuzzy logic controller vs. PI controller for MPPT of three-phase grid-connected PV system considering different irradiation conditions," Journal of Intelligent \& Fuzzy Systems, vol. 30, pp. 1353-1366, 2016.

[12] R. Khanna, Q. Zhang, W.E. Stanchina, G.F. Reed, Z.-H. Mao, "Maximum power point tracking using model reference adaptive control", IEEE Trans. Power Electron., vol. 29, no. 3, pp. 1490-1499, 2014.

[13] K. Ishaque, Z. Salam, M. Amjad, S. Mekhilef, "An improved particle swarm optimization (PSO)-based MPPT for PV with reduced steady-state oscillation", IEEE Trans. Power Electron., vol. 27, no. 8, pp. 3627-3638, 2012.

[14] Lala Septem Riza, Aldi Zainafif, Rasim3, Shah Nazir, "Fuzzy Rule-based Classification Systems for the Gender Prediction from Handwriting," TELKOMNIKA (Telecommunication, Computing, Electronics and Control), vol.16, no. 6, pp. 2725-2732, 2018.

[15] Norazlan Hashim, Zainal Salam, Dalina Johari, Nik Fasdi Nik Ismail, "DC-DC Boost Converter Design for Fast and Accurate MPPT Algorithms in Stand-Alone Photovoltaic System," International Journal of Power Electronics and Drive System (IJPEDS), vol. 9, no. 3, pp. 1038-1050, 2018. 